\title{
Distance English Education in the Era of "Internet+"
}

\author{
Wei Li \\ Xinyang Agriculture and Forestry University, Xinyang Henan 464000, China. \\ 39966736@qq.com
}

\begin{abstract}
Contraposing communication absence in modern distance education, and under this paper exploringly designs and puts forward an "Internet+" Model Based on Expression Recognition, "Internet+" is its theoretic foundation, its kernel technology estimates and comprehends learner's communication states by catching and recognizing their motion, then presents corresponding communicative encouragement and communicative compensability strategies according to their given communication states. It promotes HCI, abates the communication absence problem in modern distance education for some degrees, and does some profitable foundational works for solving the communication absence and realizing Harmonious HCI in modern distance education.
\end{abstract}

Keywords: Modern distance education; "Internet+"; motion recognition.

\section{Introduction}

"Internet+" is a hotspot problem in information science, cognition science and psychology studies, it bases on human being's communication and affection, studies communication mechanism, communicative signal capturing, communicative mode recognizing, communication modeling and comprehending, communication synthesizing and expressing, communication transferring and alternating, and so on. Its final aim is endowing computer with the communicative ability similarly with human beings. Communication model will be described by Figure 1, the producing mechanism of human behavior mainly depends on the external stimuli and the existing real-time communication, so considering this issue on change mechanism change of the communication, consideration must be given to external stimuli and with feelings signal at the time. Communicational learning process mainly completed by the amygdala.

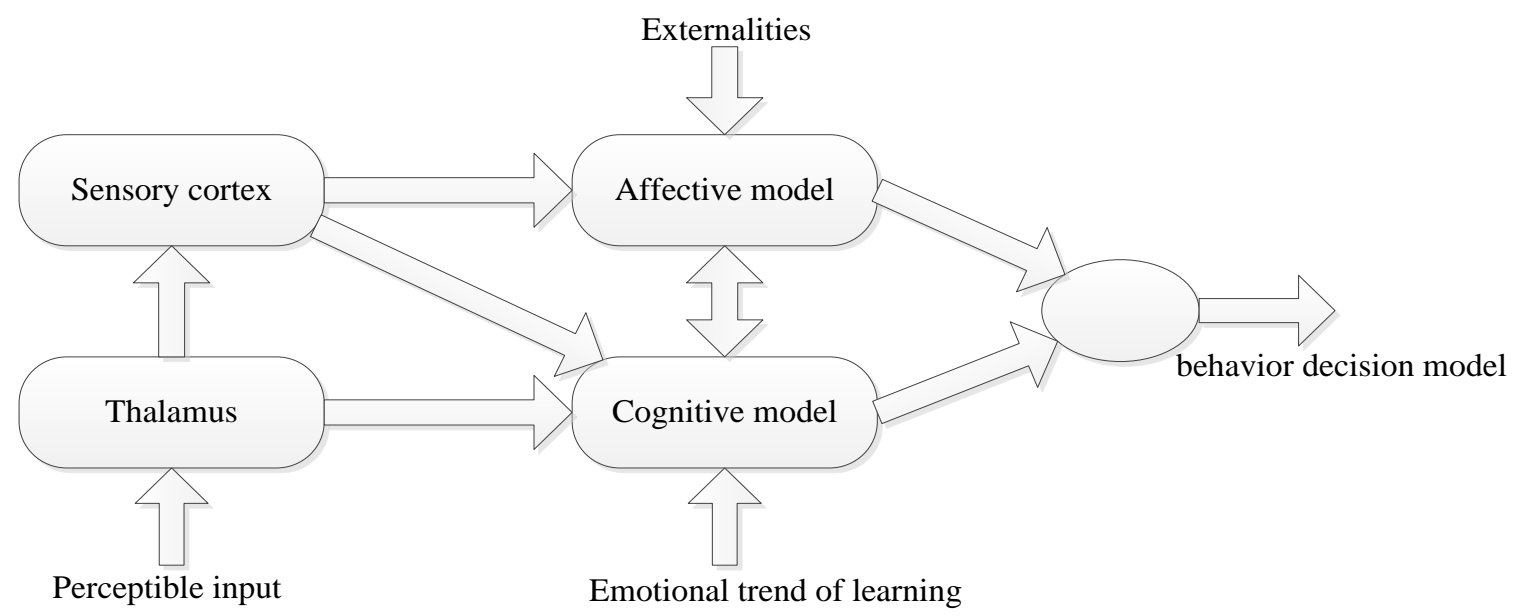

Fig 1 communication model

Communicational design is a kind of communicational designing concept that is developed in USA, this concept thought that the true value of products is to meet the user's communicational needs, the purpose of which is to make communication into products through a variety of shapes, colors, mechanism and other designing elements, when consumers use the products, people can get the spirit of joy and feel satisfied and pleased, stimulate people's imagination and even produce resonance. Professor Donald Norman thought, design can be divided into three levels: automatic pre-set layer, which can also be called as Visceral level; the level contains the control behavior of common brain activity, which also can be called as Behavioral level; the level of brain's thinking, which also can be called as Refleetive level, shown in Fig.2. 


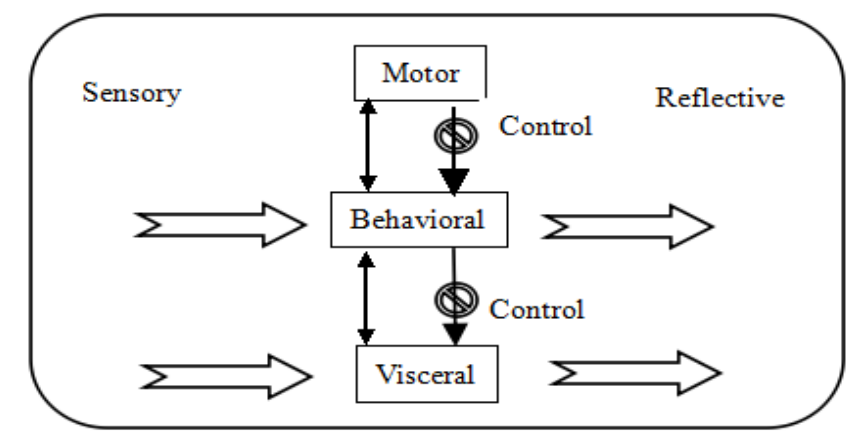

Fig 2 Level of communicational Design

\section{Statistical Model of Hidden Markov Model for Communication Modeling}

Due to the non-stationary random signal, the level of communication and the communication unobservable of sports students' sensibility signals, in the establishment of communication model, will use the HMM process simulation of human psychological activity process, thus establishing the main communication model HMM communication. Hidden Markov model H (hidden Markov Model, referred to as HMM) is a kind of statistical signal model, which was Markov signal source or Markov chain based on probability function, and proposed in twentieth Century at the end of the 60's and early 70 's.It is a parametric representation, used for describe the probability model to describe the statistical properties of the random process. As shown in fig 3

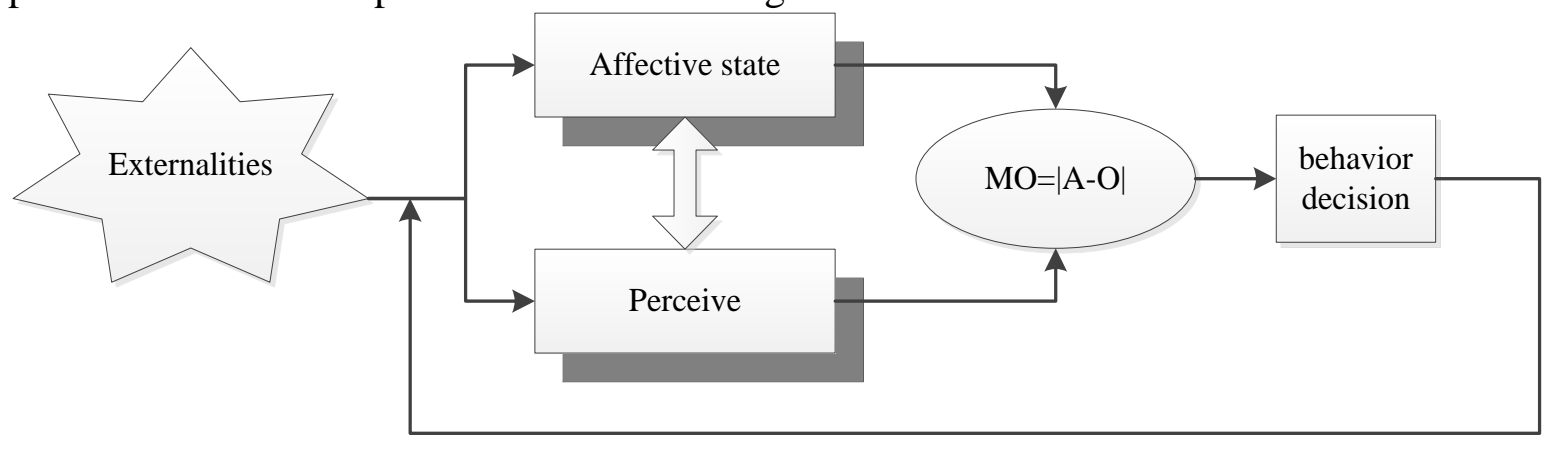

Fig 3 Hidden Markov model

\section{The Realization of Communicational English Education Model Based on Communicative Interaction}

Modern distance English education led to a profound change in education mode and education idea. It adopts advanced technology and means of education, will be through the computer network extends to every corner of the society, broke the learning time, space and personnel constraints, learners can learn independently at the appropriate time and place [3]. But based on the current PE teaching system in the concept of remote location, network system and the two-way interaction and other areas there are still shortcomings; especially in the two-way interaction, time and space of modern long-distance English education separation makes learners cannot meet the communicational communication and the existence of communication absence, this will affect the students' cognitive learning, even mental health, so and communicational compensation has important significance for guaranteeing the quality of teaching of modern long-distance English education and improve the teaching effect of modern long-distance English education. In this paper, with the communicational entropy as one of the constraints, to construct the initial state of communication model of transfer matrix, provides a quantitative calculation method for virtual human character formation. And the analysis of communicative model test results show that communicational reaction model simulation is consistent with the law of human communicative behavior. Communication model make stiff, cold machine into a "virtual human with", to the harmonious human-computer interaction a step forward [4]. 
In the design of the communicational model, first of all, we aimed at the most simple modeling:

(1)Hypothesis mood divided into: general, good mood, bad in three cases, the number of state corresponding to $\mathrm{M}=3$ in a hidden Markov model;

(2)Expression is divided into: expressionless, joy, no joy in three cases, corresponding the number of $\mathrm{N}=3$ in hidden Markov model to observe;

In the model, any state can be reached from any other state (a step), strictly speaking, and properties of model is: any state can be reached from any other state in a finite number of steps. This model has the properties: each AIJ coefficient is positive, that is, for any $\mathrm{i}, \mathrm{j}$ are ${ }^{a_{i j}>0}$, only $\mathrm{C}$ ), $\mathrm{O}$ (vIG), 0 (vIB) expressed respectively the emerging observe sequence value for the general, the good and the bad condition in the mood.

The probability of initial probability vector corresponding to the communicational model training before the start of each mood appears [5]. According to the history external stimulation of different and specific character, can be give the corresponding initial probability vector. The mood fluctuations decay with the increase of time, unless a new incentive. There foremost of the time people in a calm state of mind. When a virtual human at the first time and human interaction, because before this has not received any incentive, so at this point, it should be in a calm state of mind, with human-computer interaction, her communications in accordance with the characteristics of human communicational response, and gradually accumulated and change. From the above analysis, we can determine when the virtual people without incentive effect on the initial probability

Vector $\pi=(\pi 1, \pi 2, \pi 3)=(1,0,0)$

That calm state probability is 1 , the probability of state of happy and unhappy state are 0 . With the development of human-computer interaction, virtual human communications in accordance with the characteristics of human communicational reaction, gradually accumulated, change. On the excitation signal of communicational awareness, we focus on stimulus. The consciousness form of the people although varied, but the human is like every other animal, accepted the most or the "reward" and "punishment" signal. "Reward" signal refers to the signal stimulation of the brain's pleasure center: "punish" refers to the signal stimulation of the brain's unhappy. Because of this, our communicational system mainly these two sensing signal response. In the course of programming, we will signal quantization into two dimensions, namely positive stimuli consisted of "a little reward" and "reward" signal, negative stimuli consisted of "a little punishment" and "punishment" signal. Accept different signal, corresponding to different communication model parameters, as shown in Table 1.

Table 1 different communication model parameter

\begin{tabular}{|c|c|c|c|}
\hline $\begin{array}{c}\text { Stimulus } \\
\text { signals }\end{array}$ & $\begin{array}{c}\text { communicational model } \\
\text { parameters }\end{array}$ & $\begin{array}{c}\text { Stimulus } \\
\text { signals }\end{array}$ & $\begin{array}{c}\text { communicational model } \\
\text { parameters }\end{array}$ \\
\hline A little reward & $\mathrm{AR}(1), \mathrm{BR}(1), \mathrm{OR}(1)$ & A little punish & $\mathrm{AP}(1), \mathrm{BP}(1), \mathrm{OP}(1)$ \\
\hline Reward & $\mathrm{AR}(2), \mathrm{BR}(2), \mathrm{OR}(2)$ & Punish & $\mathrm{AP}(1), \mathrm{BP}(1), \mathrm{OP}(1)$ \\
\hline
\end{tabular}

We are in different combinations for communicational virtual human different stimulation, can get communicational reaction results of virtual human. Simulation study is performed using MATLAB software. We put the subliminal stimuli, divided into four types: "a little award", "award", "a little punishment" and "punishment". Thus, for each stimulus were corresponding a state transition probability matrix and visible symbol probability matrix. For the selection of initial value used for the model revaluation of the state transition rules matrix and visible symbol probability matrix, can be determined by experience, at the same time, want to consider the effect to external stimuli of various mentality communication entropy, makes the role communicational entropy consistent with individual characteristics. We are located in accepting the "reward" signal, virtual human communication mainly communicational state transition probability moment Array. 


\section{Conclusion}

Motion recognition means distills and analyzes motion information of human, classifies and comprehends according to human's cognition and thinking manners, makes computer thinking and reasoning by using transcendent knowledge about human's communication, then analyzes and comprehends human's communication, it is a research field and development direction of "Internet+"g.

\section{References}

[1] Zuo, M., Introduction to communicational interaction in network teaching. Audio-visual education in China, 2, (2008).

[2] Hao, N., from the perspective of education psychology defects existing in the current network education. Electrochemical education research, 8, 12, 232-241 (2002).

[3] Li, M. P., "Internet+"g theory and technology. Systems engineering and electronics. 7, (2003).

[4] Picard R W. Computers that recognize and Respond to User communication: Theoretical and Practical Implications MIT Media Lab Tech Report, 1995.

[5] Abboud B. Davoine F. Dang M Statistical modeling for facial expression analysis and synthesis. IEEE International Conference on Image Processing. 2003 .p:4--17. 